\title{
Semen quality in papaya workers with long term exposure to ethylene dibromide
}

\author{
JENNIFER M RATCLIFFE, ${ }^{1}$ S M SCHRADER, ${ }^{2}$ K STEENLAND ${ }^{1}$ D E CLAPP, ${ }^{1}$ \\ T TURNER, ${ }^{2}$ R W HORNUNG ${ }^{3}$
}

From the Industrywide Studies Branch, ${ }^{1}$ Division of Surveillance, Hazard Evaluations and Field Studies, Experimental Toxicology Branch, ${ }^{2}$ Division of Biomedical and Behavioural Science, and Support Services Branch, ${ }^{3}$ Division of Surveillance, Hazard Evaluations and Field Studies, National Institute for Occupational Safety and Health, Cincinnati, Ohio 45226, USA

ABSTRACT To examine whether long term occupational exposure to ethylene dibromide (EDB) affects semen quality a cross sectional study of semen quality was conducted among 46 men employed in the papaya fumigation industry in Hawaii, with an average duration of exposure of five years and a geometric mean breathing zone exposure to airborne EDB of $88 \mathrm{ppb}$ (eight hour time weighted average) and peak exposures of up to $262 \mathrm{ppb}$. The comparison group consisted of 43 unexposed men from a nearby sugar refinery. Statistically significant decreases in sperm count per ejaculate, the percentage of viable and motile sperm, and increases in the proportion of sperm with specific morphological abnormalities (tapered heads, absent heads, and abnormal tails) were observed among exposed men by comparison with controls after consideration of smoking, caffeine and alcohol consumption, subject's age, abstinence, history of urogenital disorders, and other potentially confounding variables. No effect of exposure to EDB on sperm velocity, the overall proportion of sperm with normal morphology, or YFF bodies was observed. These data strongly suggest that EDB may increase the risk of reproductive impairment in workers at exposure levels near the National Institute for Occupational Safety and Health recommended limit of $45 \mathrm{ppb}$ (as an eight hour time weighted average) and far below the current standard of the Occupational Safety and Health Administration of $20 \mathrm{ppm}$.

Ethylene dibromide (EDB; also called dibromoethane) has been widely used in the United States as a scavenger in leaded petrol and as an active component of about 100 pesticides used as soil, fruit, grain, and timber fumigants. The National Institute for Occupational Safety and Health (NIOSH) estimated in 1977 that about 108000 workers (principally in manufacturing and formulating industries) were potentially exposed to $\mathrm{EDB}^{1}$; an unknown number of agricultural workers have also been potentially exposed to EDB, although this number is declining owing to restrictions placed on the use of EDB as a pesticide by the Environmental Protection Agency (EPA) since $1983 .^{2}$ The Occupational Safety and Health Administration (OSHA) has proposed a reduction in their current standard from $20 \mathrm{ppm}$ $(20000 \mathrm{ppb})$ to $100 \mathrm{ppb}$ as an eight hour time weighted average (TWA) ${ }^{3}$; the NIOSH recommended standard is $45 \mathrm{ppb}$ (eight hour TWA) with a 15

Accepted 28 May 1986 minute ceiling limit of $130 \mathrm{ppb} .^{4}$ EDB is a highly reactive alkylating agent, is mutagenic in several experimental systems, and carcinogenic in animals. ${ }^{15}$ Animal studies have shown the effects of EDB on semen quality and fertility in several species. Decreases in sperm concentration and percentage motility and increases in abnormal sperm morphology have been observed in bulls after oral administration. ${ }^{6-10}$ Dose dependent increases in abnormally shaped sperm and decreases in the percentage of motile sperm were observed in rams after subcutaneous dosing ${ }^{11}$ but not after oral administration at comparable doses. ${ }^{12}$ Finally, reductions in average litter sizes in untreated female rats and mice were reported by Edwards et al ${ }^{13}$ when mated with males given $10 \mathrm{mg} / \mathrm{kg}$ EDB intraperitoneally for five days and in rats mated with males given 39 ppm EDB by inhalation for 10 weeks. ${ }^{14}$

There have been few previous attempts to evaluate fertility or semen quality among male workers exposed to EDB. In one published study of birth rates 
among wives of men exposed to EDB compared with United States national rates a statistically significant decrease in the observed/expected birth ratio was found for one of four plants where EDB was used. ${ }^{15}$ In previous investigations of sperm characteristics small sample sizes, lack of specification of the methods of sample collection and analysis, or lack of comparison groups and exposure data have resulted in inconclusive findings. ${ }^{15-20}$ Furthermore, previous investigators have not examined a range of sperm characteristics (including viability, motility, and morphology) which may affect male fertility, with the exception of a longitudinal study of timber fumigators with short term exposure to EDB using identical methods as those described in the present study, ${ }^{20}$ in which a statistically significant decrease in sperm velocity was observed when pre- and postexposure samples were compared.

To investigate the potential mutagenicity and spermatotoxicity of EDB among workers with long term exposure, we conducted a cross sectional combined cytogenetic and semen study among male workers exposed to EDB used in the treatment of papaya for fruit fly infestation on the island of Hawaii. This report describes the study of semen characteristics; the results of the cytogenetic study are presented elsewhere. $^{21}$

\section{Materials and methods}

\section{DESCRIPTION OF PLANTS}

Six fumigation plants were investigated in this study, all located in or near Hilo, Hawaii, and employing a total of about 75 men and 115 women. Most plants consist of a single work area where fumigated fruit is sorted and packed with a fumigation chamber often opening into the same room. EDB is introduced into the fumigation chamber in pure liquid form in a closed system and evaporated to a gas by heating. Packers and sorters generally work inside all day and rarely enter the fumigation chamber. Forklift drivers and fumigators frequently enter the chamber but also work outside for periods of the day. No respirators or other personal protective equipment are used. There is little opportunity for skin exposure except for accidental spillages of liquid EDB.

\section{EXPOSURE MEASUREMENT}

Two industrial hygiene surveys of these plants were conducted a year before and during the semen and cytogenetic study and are described in detail elsewhere. ${ }^{22}$ Samples were collected in all plants on at least two separate days and workers were sampled for a full eight hour shift unless their duty cycle indicated a shorter sampling period. Several short term (14-75 minutes) measurements of exposures during entry into the fumigation chamber by fumigators and forklift drivers were also conducted. A total of 82 full shift and 19 short term samples was collected on activated charcoal tubes and analysed by gas liquid chromatography according to NIOSH standard method $1008 .^{23}$

\section{SELECTION OF PARTICIPANTS}

Personnel lists of all male workers currently employed at five of the six plants (the sixth was located at the time of the field survey) were obtained and letters sent to each man explaining the purpose of the study. Each man was subsequently interviewed confidentially to ask him to participate. Seventy two per cent of currently employed workers from the first five plants agreed to participate; approximately $33 \%$ of these at the sixth plant, who were contacted only at the time of the field survey, also agreed (total 64\%). Two workers with less than two months employment were excluded. Workers in a sugar processing plant adjacent to one of the papaya treatment plants who had minimal exposure to chemical and physical hazards were identified as a suitable control group of similar ethnic background, socioeconomic status, and age. Letters were circulated to each of the approximately 200 male workers explaining the purpose of the study and the first 50 workers who volunteered to participate were selected as controls.

\section{QUESTIONNAIRE AND SEMEN COLLECTION}

$A$ detailed questionnaire was administered by personal interview to provide data on personal and demographic data, medical history, smoking and drinking habits, work history, and current and previous exposures to chemical and physical hazards. Subjects were asked to collect a semen specimen at home by masturbation into a coded, sterile glass jar after a minimum of two days and preferably less than five days of abstinence, to place the sample in the thermos flask provided, and to bring it to the laboratory within one hour of collection. The data and time of ejaculation, abstinence period, and spillage (if any) were recorded on the jar label by the subject. Semen samples were received from a total of 48 exposed and 43 unexposed subjects $(96 \%$ and $86 \%$ respectively of those who agreed to participate). Two exposed men were found to be azoospermic. Subsequent medical examination of these men determined the cause to be Klinefelter's syndrome and bilateral cryptorchidism respectively, and they were eliminated from further analysis.

\section{SEMEN ANALYSIS}

Semen analyses were conducted in two phases. Video recordings, viability assessments, sperm counts, volume and $\mathrm{pH}$ measurements, fixation of slides, and 
cryopreservation of seminal plasma were conducted at the field study location. Morphology and morphometry analyses of slides and motility and velocity analyses of video tapes were conducted at NIOSH laboratories. All samples were processed and analysed blind by the investigators.

\section{Sperm velocity and motility}

Seven microlitres of the semen sample were placed on a glass slide under a coverslip and placed on a microscope stage warmed to $37^{\circ} \mathrm{C}$ by a heat curtain. Five to eight fields selected arbitrarily were video recorded with a $25 \times$ phase objective, a video recorder, vertical enhancer, and high resolution camera and monitor. The time from ejaculation to videotaping (sample age) was recorded. Video tapes were analysed using a semiautomatic image analysis system with video overlay and digitising tablet. For sperm velocity measurements, 30 motile sperm ${ }^{24}$ from each sample were randomly selected, the path of each was digitised, and the start and stop times (to the nearest 0.01 second) for each tracing were recorded. Sperm velocity was measured both as velocity along the actual sperm path and straight line (point to point or distance) velocity. 2526

The percentage of motile sperm was determined by marking all sperm observed in one video frame, then advancing the video tape to identify motile and nonmotile sperm. This process was repeated for a minimum of five fields, so that an average of 200 sperm were scored.

\section{Semen $\mathrm{pH}$ and volume}

The $\mathrm{pH}$ of the semen sample was determined using a $\mathrm{pH}$ meter equipped with a gel filled plastic $\mathrm{pH}$ electrode. The volume was measured using a $5 \mathrm{ml}$ plastic disposable syringe.

\section{Sperm morphology and morphometry}

Four air dried smears were prepared from each whole semen sample, fixed in absolute ethanol for ten minutes, and stored for later analysis. Slides were stained in Papanicolaou stain according to World Health Organisation semen analysis guidelines. ${ }^{27}$ Sperm morphology was scored according to Zaneveld and Polakoski, ${ }^{28}$ reading 200 cells on each of two slides. The remaining two slides were used for objective analysis of sperm head shape (morphometry) using a $63 \times$ dry objective and video camera with a $4 \times$ enlarger to evaluate 100 sperm on each of two slides. Individual sperm heads were outlined using the digitising tablet and the software allowed calculations of area, perimeter, length, width, width/length ratio, and $4 \mathrm{pi}$ (area)/perimeter ${ }^{2}$ (Pi factor).

\section{Sperm viability}

Viability by strain exclusion, modified from Eliasson and Treichl ${ }^{29}$ was determined by mixing $100 \mu$ l of semen with $100 \mu \mathrm{l}$ of $0.5 \%(\mathrm{w} / \mathrm{v})$ eosin $\mathrm{y}$ stain in Tyrodes buffer. A $7 \mu$ l sample was placed on a slide and 200 sperm classified as unstained (viable) or stained (non-viable). Viability by hypo-osmotic swelling ${ }^{30}$ was analysed by mixing $100 \mu \mathrm{l}$ of semen with $1.0 \mathrm{ml}$ of a solution containing 150 milliosmolar sodium citrate and 150 milliosmolar fructose. After an incubation of at least 30 minutes (after which further swelling does not occur) $7 \mu \mathrm{l}$ were placed on a slide, and 200 sperm were classified as swollen (viable) or unswollen (non-viable) using differential interference contrast (DIC) microscopy.

\section{Sperm concentration}

One hundred microlitres of semen were mixed with $100 \mu$ of distilled water. Five microlitres of this suspension were placed on a Makler Chamber and the sperm were counted using DIC microscopy. Replicates were prepared and counted for each sample.

\section{YFF bodies}

The YFF sperm assay is a quantification of the incidence of sperm with two fluorescent bodies (YFF bodies) and has been proposed as a measure of $Y$ chromosomal non-disjunction. ${ }^{31}$ Semen samples were analysed according to the method of Kapp and Jacobsen. ${ }^{31}$ Semen smears were stained with quinacrine dihydrochloride and scored under fluorescent microscopy for the number of sperm with zero, one, and two fluorescent bodies, expressed as a percentage of the total number of sperm counted. Only normal (oval) sperm heads were counted. In most cases 500 sperm were counted; in a few cases 100,240 , or up to 520 sperm were counted, depending on the number of normal sperm observed on the smear. Replicate slides were read for about half the samples, and eight slides were read twice to assess reader repeatability.

\section{STATISTICAL ANALYSIS}

Data for each semen characteristic were tested for normality using the Shapiro-Wilk statistic for sample sizes of less than $51 . .^{32}$ In the case of proportions-for example, the percentage of motile or viable spermlogistic transformations of the data were used; for all other data that were not normally distributed, the least severe transformation that did not significantly depart from normality was used. (In the case of sperm concentration, a square root transformation was used; natural lcg transformations were used for semen volume, distance velocity, and area and width of sperm heads.) Variables were analysed using two sided $t$ tests and least squares linear regression analysis, except for abnormal sperm classifications, which were analysed using the FUNCAT procedure for multinomial data. ${ }^{33}$ This procedure permits the 
Table 1 EDB exposure by job category and plant (parts per billion*) for full shift personal samples

\begin{tabular}{|c|c|c|c|c|c|c|}
\hline \multirow[b]{2}{*}{ Job category } & \multicolumn{6}{|c|}{ Full shift samples } \\
\hline & Plant I & Plant 2 & Plant 3 & Plant 4 & Plant 5 & Plant 6 \\
\hline $\begin{array}{l}\text { Sorter/packer } \\
\text { Forklift driver } \\
\text { Fumigator }\end{array}$ & $\begin{array}{l}36(n=13) \\
51(n=4) \\
N A\end{array}$ & $\begin{array}{l}66(n=12) \\
92(n=4) \\
\text { NA }\end{array}$ & $\begin{array}{c}65(n=16) \\
175(n=4) \\
116(n=2)\end{array}$ & $\begin{array}{r}49(\mathrm{n}=6) \\
152(\mathrm{n}=2) \\
\mathrm{NA}\end{array}$ & $\begin{array}{l}72(n=9) \\
16(n=3) \\
\text { NA }\end{array}$ & $\begin{array}{l}148(n=7) \\
\text { NA } \\
\text { NA }\end{array}$ \\
\hline
\end{tabular}

* Limit of detection for EDB is $0.02 \mathrm{ppb}$.

Data shown are geometric means ( $n=$ number of men sampled).

NA $=$ Not available (samples not taken at these plants).

simultaneous analysis of the frequency of responses in each category of abnormal sperm (by comparison with the proportion of normal forms) to produce approximate chi squared statistics. The following potentially confounding variables and effect modifiers were considered a priori for inclusion in the regression models: tobacco smoking (current, ex-, and non-smokers), marijuana use (times a week), alcohol consumption (drinks a week), caffeine consumption (cups of coffee or tea or both a day), history of urogenital disorders and prescription medication use in the preceding year, history of fever in the preceding three months, abstinence time, sample age, and subject's age and ethnic background. Treatment of potentially confounding variables was done by considering variables for inclusion in the regression model using a forward and backward stepwise technique with exposure forced into the model; variables were excluded from the model if the $p$ value of the coefficient was greater than $0 \cdot 1$ and the variable had a negligible effect on the exposure variable. Assessment of factors for modification of the exposure effect was done by the introduction of two factor interaction terms with the exposure variable. ${ }^{34}$

To reduce the likelihood of a false positive result due to multiple comparisons a highly conservative approach is to use a Bonferroni correction factor to obtain the acceptable level of statistical significance for each test. ${ }^{35}$ An alternative approach was adopted in the present analysis by taking groups of multiple or closely correlated measurements and performing a test of the overall significance of the independent variables included in the regression model on the group of dependent variables, using the MANOVA procedure. $^{33}$ For the analysis of abnormal sperm morphology classification, a $p$ value of 0.001 or less was considered an acceptable level of significance due to the large number ( 200 per subject) of observations in the model.

\section{Results}

\section{EXTENT OF EXPOSURE}

The results for breathing zone exposures to EDB are summarised in table 1 . The results from both sam- pling periods were similar and have been combined $\overrightarrow{\vec{\omega}}$ Full shift exposures ranged from an average of $16 \mathrm{pp} / 8$ (forklift drivers in plant 5) to $175 \mathrm{ppb}$ (forklift driver\$ in plant 3) with a geometric mean of $88 \mathrm{ppb}$, and were generally below the proposed OSHA eight hour TWA standard of $100 \mathrm{ppb}$ and far below the current stan $\mathrm{O}$ dard of $20 \mathrm{ppm}(20000 \mathrm{ppb})$. Numerous individuat samples exceeded the NIOSH recommended eighb hour TWA of $45 \mathrm{ppb}$ and the ceiling limit of $130 \mathrm{ppb}$ Analysis of variance showed no significant differences across either job categories or plants, althougtw exposures were higher in plant 6 (mean $148 \mathrm{ppb}$ ) where packing and sorting were done in the fumio gation chamber itself. The geometric mean of the short term exposures for forklift drivers was $87 \mathrm{pp} b$ and for fumigators, $40 \mathrm{ppb}$; exposures ranged from 125 to $262 \mathrm{ppb}$. The lower full shift values for these work ers may be attributed to the fact that they also spenof more time outside the plant than packers and sorters $\stackrel{\mathbb{Q}}{\Phi}$

Table 2 Characteristics of exposed and unexposed workers

\begin{tabular}{|c|c|c|}
\hline Characteristic & $\begin{array}{l}\text { Unexposed } \\
(n=43)\end{array}$ & $\begin{array}{l}\text { Exposed } \\
(n=46)\end{array}$ \\
\hline Age (years) (mean \pm SD) & $34 \cdot 4 \pm 10 \cdot 1$ & $28.9 \pm 10$ \\
\hline Ethnic background (\%): & & \\
\hline White & $21 \cdot 0$ & $13 \cdot 0$ \\
\hline Filipino & $49 \cdot 0$ & $28 \cdot 0$ \\
\hline Japanese & $14 \cdot 0$ & $11 \cdot 0$ \\
\hline Hawaiian & $2 \cdot 0$ & $15 \cdot 0$ \\
\hline $\begin{array}{l}\text { Mixed (Asian, Pacific Islander, } \\
\text { white) }\end{array}$ & $14 \cdot 0$ & 33.0 \\
\hline Cigarette smokers (\%): & & \\
\hline Current smoker & $37 \cdot 2$ & $41 \cdot 3$ \\
\hline Ex-smoker & $34 \cdot 9$ & $19 \cdot 6$ \\
\hline Non-smoker & $27 \cdot 9$ & $39 \cdot 1$ \\
\hline $\begin{array}{l}\text { Alcohol consumption (drinks/week) } \\
(\text { mean } \pm \mathrm{SD})\end{array}$ & $9 \cdot 1 \pm 9 \cdot 1$ & $11.9 \pm 15$ \\
\hline $\begin{array}{l}\text { Caffeine consumption (cups tea/coffee/ } \\
\text { day (mean }+ \text { SD) }\end{array}$ & $2 \cdot 0+2 \cdot 1$ & $1.9+3.2$ \\
\hline Use of prescription medication in & & \\
\hline $\begin{array}{l}\text { preceding year }(\%) \\
\text { Use of marijuana }(\%)\end{array}$ & $48 \cdot 8$ & $41 \cdot 3$ \\
\hline History of urogenital disorders (\%) & 0.0 & $\begin{array}{r}41 \cdot 3 \\
6 \cdot 5\end{array}$ \\
\hline Fever in preceding 3 months $(\%)$ & $4 \cdot 7$ & $15 \cdot 0$ \\
\hline$($ mean $\pm S D)$ & $4 \cdot 2 \pm 4 \cdot 9$ & $5.8 \pm 9.9$ \\
\hline $\begin{array}{l}\text { Time from semen sample collection to } \\
\text { analysis (minutes) (mean } \pm \text { SD) }\end{array}$ & $39 \cdot 0 \pm 17 \cdot 1$ & $39 \cdot 4 \pm 18$ \\
\hline $\begin{array}{l}\text { Duration of employment (yrs) } \\
\text { (mean } \pm \text { SD) }\end{array}$ & $11 \cdot 0 \pm 8 \cdot 1$ & $4.9 \pm 3.6$ \\
\hline
\end{tabular}

SD = Standard deviation of the mean. 
Table 3 Semen volume, sperm concentration, and count in exposed and unexposed workers

\begin{tabular}{|c|c|c|c|c|c|}
\hline \multirow[b]{2}{*}{ Characteristic } & \multicolumn{2}{|c|}{ Unexposed $(n=43)$} & \multicolumn{2}{|c|}{ Exposed $(n=46)$} & \multirow[b]{2}{*}{$p \S$} \\
\hline & Mean & $S D$ & Mean & $S D$ & \\
\hline $\begin{array}{l}\text { Semen volume }(\mathrm{ml}) \\
\text { Adjusted mean* } \\
\text { Sperm concentration (million/ml) } \\
\text { Adjusted mean } \dagger \\
\text { Sperm count (million/ejaculate) } \\
\text { Adjusted mean }+ \\
\% \text { Subjects with sperm concentration } \leqslant 20 \text { million } / \mathrm{ml}\end{array}$ & $\begin{array}{r}2 \cdot 78 \\
2 \cdot 53 \\
68 \cdot 72 \\
59 \cdot 39 \\
204 \cdot 80 \\
139 \cdot 76 \\
4 \cdot 7\end{array}$ & $\begin{array}{r}1.54 \\
47 \cdot 50\end{array}$ & $\begin{array}{r}2 \cdot 57 \\
2 \cdot 11 \\
52 \cdot 57 \\
48 \cdot 37 \\
134 \cdot 82 \\
80 \cdot 99 \\
21 \cdot 7\end{array}$ & $\begin{array}{r}1.39 \\
42.06 \\
138.49\end{array}$ & $\begin{array}{l}\text { NS } \\
<0.01 \\
0.03 \|\end{array}$ \\
\hline
\end{tabular}

NS $=$ Not significant $(p>0.05)$.

*Adjusted for abstinence $(p=0.02)$ and subject's age $(p=0.04)$.

†Adjusted for abstinence $(\mathrm{p}<0.01)$, subject's age $(\mathrm{p}=0.03)$, and ethnicity (whites $v$ non-whites; $\mathrm{p}<0.01)$, and caffeine consumption ( $\mathrm{p}=$ 0.01 ).

†djusted for abstinence $(p<0.01)$.

$\S$ Two sided $\mathrm{p}$ value for the effect of exposure adjusted for other factors in the regression model or $\|$ two sided Fisher's exact test.

and particularly in the smaller plants, reported multiple job assignments.

\section{CHARACTERISTICS OF THE GROUPS}

The exposed and unexposed groups are generally similar for characteristics determined by questionnaire (table 2). The mean ages of the two groups were significantly different $(\mathrm{p}=0.01)$; a higher proportion of exposed workers were aged 26 or under $(46 \%$ compared with $14 \%$ in the unexposed group). A higher proportion of the unexposed group were white or Filipino. The two groups did not differ significantly with respect to recent fever; alcohol, caffeine, cigarette, or prescription medication consumption; and history of urogenital disorders, but a significantly higher proportion of exposed workers reported the use of marijuana $(\mathrm{p}=0.05)$.

\section{SPERM CHARACTERISTICS}

Analysis by exposure group

Semen volume, sperm concentration, and countThe mean semen volume was not significantly different between the exposed and unexposed groups; it was lower in the exposed group than the unexposed group after adjustment for abstinence and subject's age as significant confounders (table 3). Similarly, sperm concentration was lower in the exposed group, but after adjustment for abstinence, the subject's age and ethnic background, and caffeine consumption, this difference was not significant. A significantly higher proportion of exposed men, however, had oligospermia (sperm concentrations of less than 20 million per $\mathrm{ml})(21.7 \% \vee 4.7 \%$; $\mathrm{p}=0.03)$. (There were no azoospermic men other than the two previously excluded from analysis.) When sperm count per ejaculate was considered, the effect of exposure was highly significant $(p<0.01)$ after correction for abstinence as the only significant confounder. (Note that the semen $\mathrm{pH}$ of exposed subjects was significantly more alkaline than that of unexposed subjects $(8.01 v 7.9 ; \mathrm{p}=0.03)$ after consideration of other factors (data not shown); however, subsequent analyses suggest that some drift in $\mathrm{pH}$ may occur

Table 4 Sperm viability and motility in exposed and unexposed workers

\begin{tabular}{|c|c|c|c|c|c|}
\hline \multirow[b]{2}{*}{ Characteristic } & \multicolumn{2}{|c|}{ Unexposed $(n=43)$} & \multicolumn{2}{|c|}{ Exposed $(n=45) \ddagger$} & \multirow[b]{2}{*}{$p \S$} \\
\hline & Mean & $S D$ & Mean & $S D$ & \\
\hline $\begin{array}{l}\text { Sperm viability by stain exclusion (\%) } \\
\text { Adjusted mean } \\
\text { Sperm viability by hypo-osmotic stress (\%) } \\
\text { Adjusted mean* } \\
\text { Sperm motility }(\%) \\
\text { Adjusted mean* } \\
\text { Path length velocity }(\mu \mathrm{m} / \mathrm{sec}) \\
\text { Adjusted mean } \dagger \\
\text { Distance velocity }(\mu \mathrm{m} / \mathrm{sec}) \\
\text { Adjusted mean }{ }^{*}\end{array}$ & $\begin{array}{l}72 \cdot 98 \\
75 \cdot 40 \\
74 \cdot 30 \\
85 \cdot 47 \\
44 \cdot 93 \\
46 \cdot 58 \\
68 \cdot 48 \\
69 \cdot 06 \\
43 \cdot 18 \\
42 \cdot 95\end{array}$ & $\begin{array}{r}8.74 \\
9.09 \\
14.22 \\
10.75\end{array}$ & $\begin{array}{l}68 \cdot 07 \\
67 \cdot 09 \\
68 \cdot 46 \\
68 \cdot 13 \\
40 \cdot 94 \\
35 \cdot 21 \\
71 \cdot 80 \\
71 \cdot 25 \\
42 \cdot 94 \\
41 \cdot 26\end{array}$ & $\begin{array}{l}15.76 \\
12.86 \\
18.02\end{array}$ & $\begin{array}{c}<0.01 \\
<0.01 \\
0.03 \\
\text { NS }\end{array}$ \\
\hline
\end{tabular}

NS $=$ Not significant ( $p>0.05)$.

*Adjusted for subject's age $(p=0.01)$

tAdjusted for alcohol consumption ( $p<0.01)$.

tOne exposed subject not included due to low sperm count.

\$Two sided $p$ value of effect of exposure adjusted for other factors in the regression model.

Significance level of MANOVA test of effect of exposure on group of dependent variables; sperm viability by vital stain and hypo-osmotic swelling and motility: $p<0.01$; path length and distance velocity; NS. 
Table 5 Sperm morphology classification in exposed and unexposed workers*

\begin{tabular}{|c|c|c|c|c|c|}
\hline \multirow[b]{2}{*}{ Category } & \multicolumn{2}{|c|}{ Unexposed $(n=43)$} & \multicolumn{2}{|c|}{ Exposed $(n=46)$} & \multirow[b]{2}{*}{$p \dagger$} \\
\hline & Mean & $S D$ & Mean & $S D$ & \\
\hline $\begin{array}{l}\text { Normal forms (\%) } \\
\text { Adjusted mean } \\
\text { Abnormal forms } \\
\text { Macrocephalic heads (\%) } \\
\text { Microcephalic heads (\%) } \\
\text { Tapered heads (\%) } \\
\text { Double heads (\%) } \\
\text { Absent heads (\%) } \\
\text { Abnormal tails (\%) } \\
\text { Immature forms (\%) } \\
\text { Amorphous heads (\%) }\end{array}$ & $\begin{array}{l}80 \cdot 16 \\
82 \cdot 72 \\
1.69 \\
1 \cdot 10 \\
2 \cdot 49 \\
0.83 \\
1.43 \\
5 \cdot 71 \\
5 \cdot 64 \\
0.61\end{array}$ & $\begin{array}{l}9 \cdot 52 \\
\\
2 \cdot 54 \\
0.99 \\
3 \cdot 17 \\
1 \cdot 47 \\
1 \cdot 29 \\
4 \cdot 45 \\
4 \cdot 71 \\
0.60\end{array}$ & $\begin{array}{l}77 \cdot 88 \\
78 \cdot 87 \\
1 \cdot 35 \\
0.99 \\
4 \cdot 21 \\
1.03 \\
2.08 \\
6.54 \\
5 \cdot 29 \\
0.64\end{array}$ & $\begin{array}{r}14 \cdot 13 \\
\\
1 \cdot 29 \\
0.99 \\
6 \cdot 22 \\
0.92 \\
1 \cdot 76 \\
10.68 \\
3 \cdot 73 \\
0.78\end{array}$ & $\begin{array}{l}\text { NS } \\
\text { p! } \\
0.04 \\
\text { NS } \\
<0.001 \\
\text { NS } \\
<0.001 \\
<0.001 \\
\text { NS } \\
\text { NS }\end{array}$ \\
\hline
\end{tabular}

from ejaculation time to time of analysis, which was not recorded for this measure in this study. Although no systematic variation in this time between exposed and unexposed subjects' samples is likely owing to intermixing and blind processing of samples, the results for semen $\mathrm{pH}$ should be interpreted with caution.)

Sperm viability, motility, and velocity-After adjustment for age of the subject (which was negatively correlated with both sperm viability and motility) the effect of exposure on both the percentage of viable sperm (by vital stain and hypo-osmotic swelling) and the percentage of motile sperm was found to be highly significant both when considered separately ( $\mathrm{p}<0.01,<0.01$, and 0.03 respectively) and as a group of characteristics in a multivariate analysis ( $p<0.01)$ (table 4). No significant effect of exposure on sperm velocity was observed, however; alcohol consumption was the only factor that differed between the exposed and unexposed groups and explained a significant amount of variation in this variable (table 4).
Sperm morphology and morphometry-The overall percentage of normal sperm (sperm with oval heads and normal tails) among exposed men was not significantly different from unexposed men before or after consideration of other factors; the subject's age and ethnic background were the only significant confounders (table 5). When all abnormal morphological classifications were considered simultaneously using the FUNCAT procedure, however, the exposed group had a significantly higher proportion of sperm with abnormal tails $(p<0.001)$, absent heads $(p<0.001)$, and tapered heads $(p<0.001)$ when corrected for age and ethnicity. (Note that the acceptable level of significance used in this analysis is $p<0.001$ as discussed above.) When representative sperm head morphometry measurements were considered (table 6) exposure was associated with a decrease in sperm head width $(\mathrm{p}<0.04)$, which agrees with the finding of a significantly increased proportion of tapered heads among the exposed group using sperm morphology analysis. The overall effect of exposure on morphometry, however, was not significant when

Table 6 Sperm morphometry in exposed and unexposed workers

\begin{tabular}{|c|c|c|c|c|c|}
\hline \multirow[b]{2}{*}{ Characteristic } & \multicolumn{2}{|c|}{ Unexposed $(n=43)$} & \multicolumn{2}{|c|}{ Exposed $(n=46)$} & \multirow[b]{2}{*}{$p^{*}$} \\
\hline & Mean & $S D$ & Mean & $S D$ & \\
\hline $\begin{array}{l}\text { Area of head }\left(\mu \mathrm{m}^{2}\right) \\
\text { Adjusted mean } \\
\text { Length of head }(\mu \mathrm{m}) \\
\text { Adjusted mean } \\
\text { Width of head }(\mu \mathrm{m}) \\
\text { Adjusted mean }\end{array}$ & $\begin{array}{l}9 \cdot 06 \\
9 \cdot 09 \\
4 \cdot 42 \\
4 \cdot 44 \\
2 \cdot 63 \\
2 \cdot 64\end{array}$ & $\begin{array}{l}1.29 \\
0.31\end{array}$ & $\begin{array}{l}8 \cdot 82 \\
8 \cdot 65 \\
4 \cdot 42 \\
4 \cdot 41 \\
2 \cdot 56 \\
2 \cdot 53\end{array}$ & $\begin{array}{l}1.07 \\
0.47\end{array}$ & $\begin{array}{l}\text { NS } \\
\text { NS }\end{array}$ \\
\hline
\end{tabular}

NS $=$ Not significant $(p>0.05)$.

*Two sided test for the effect of exposure adjusted for subject's age $(p<0 \cdot 1)$ and ethnic background $(p=0.05)$.

Significance level of MANOVA test of effect of exposure on above group of dependent variables: NS. 
Table 7 Percentage of sperm with 0,1 , or 2 YFF bodies* in exposed and unexposed workers

\begin{tabular}{|c|c|c|c|c|c|}
\hline \multirow[b]{2}{*}{ Characteristic } & \multicolumn{2}{|c|}{ Unexposed $(n=43)$} & \multicolumn{2}{|c|}{ Exposed $(n=46)$} & \multirow[b]{2}{*}{$p^{\dagger}$} \\
\hline & Mean & $S D$ & Mean & $S D$ & \\
\hline $\begin{array}{l}0 \mathrm{Y} \text { bodies } \\
1 \mathrm{Y} \text { body } \\
2 \mathrm{Y} \text { bodies }\end{array}$ & $\begin{array}{r}52.69 \\
45.98 \\
1.33\end{array}$ & $\begin{array}{l}3.69 \\
3.60 \\
0.68\end{array}$ & $\begin{array}{r}52.60 \\
46 \cdot 12 \\
1.28\end{array}$ & $\begin{array}{l}2.88 \\
2.77 \\
0.62\end{array}$ & $\begin{array}{l}\text { NS } \\
\text { NS } \\
\text { NS }\end{array}$ \\
\hline
\end{tabular}

NS $=$ Not significant $(p>0.05)$.

* Based on the first slide read per subject.

tValue of two sided $t$ test.

tested by the multivariate MANOVA procedure (table 6).

YFF bodies-The proportion of sperm with YFF bodies did not differ significantly between the exposed and unexposed groups (table 7). No other factors were found to be significantly correlated with exposure and YFF bodies.

\section{Analysis by job and duration of exposure}

To determine if a dose response relation between the effect of duration of exposure and semen quality could be observed, the data were analysed for each semen characteristic by years of exposure by comparison with controls, correcting for significant confounders. No significant linear trend with increasing duration of exposure was observed for any semen characteristic with the exception of sperm viability by vital stain $(\mathrm{p}<0.02)$, hypo-osmotic swelling $(\mathrm{p}<$ $0.01)$, and percentage motility $(p<0.03)$; in these cases longer duration of exposure was associated with poorer sperm viability and motility. No differences in sperm characteristics between workers who had potentially higher (peak) exposures (fumigators, forklift drivers, and workers in plant $6 ; n=18$ ) and other exposed workers $(n=28)$ were found when compared with unexposed workers. This may be due to the close comparability of full shift exposure levels, although small differences may not be detectable with this sample size.

\section{Discussion}

These data indicate that chronic exposure to EDB in this population is statistically significantly related to decreases in sperm count per ejaculate, the percentage of viable and motile sperm, and increases in certain types of morphological abnormalities (tapered heads, absent heads, and abnormal tails) after consideration of smoking, caffeine and alcohol consumption, subject's age, abstinence and age of sample, history of urogenital illness, and other potentially confounding factors. A significantly higher proportion of the exposed group were oligospermic, although the difference in mean sperm concentration between the two groups did not reach statistical significance after correction for confounding factors. The mean semen volume and overall proportion of normal sperm were also lower in the exposed than the unexposed group but, again, these differences were not statistically significant after consideration of other factors. No significant effect of exposure on sperm velocity or YFF bodies was observed.

As stated in the methods section, there is an increased likelihood of a false positive result when performing multiple comparisons if the acceptable level of significance for each test is not adjusted. In the present study groups of tests were tested where appropriate for the significance of exposure and other factors by multivariate techniques which yield $p$ values adjusted for the number of comparisons and improve the confidence with which a given effect may be ascribed to exposure. The effect of exposure on the group of sperm viability and motility measurements was still highly significant ( $p<0.01$; table 4 ) as on the overall group of abnormal sperm shapes $(p<0.001$; table 5). The effect of EDB exposure on sperm count per ejaculate is also highly significant $(p<0.01$; table 3 ); this appears to be a function of an effect both on semen volume and sperm concentration, suggesting that EDB may affect both spermatogenesis and seminal fluid production. This is further supported by the finding of a significantly higher proportion of oligospermic men among the exposed group. Thus even if a strictly conservative statistical interpretation was used these findings are consistent with a deleterious effect of EDB exposure on semen quality.

There was no overall effect of duration of exposure on semen quality, with the exception of sperm viability and motility, which was poorer among men with longer exposure to EDB. This finding provisionally suggests that, unless permanent damage has occurred to primary spermatogonial cells or to, for example, the hormonal control of testicular function, the effect of EDB on spermatogenesis reflects current rather than cumulative exposure owing to the constant turnover of sperm production. This is consistent with the observation in animals that recovery of normal spermatogenesis occurs after cessation of 
exposure $^{13}$ and the fact that EDB is rapidly metabolised in biological tissues. ${ }^{13}$

The results of this study are supported by previous animal data showing effects of EDB on sperm concentration, motility, and morphology (see introduction), although none of the animal studies to date has evaluated semen volume, $\mathrm{pH}$, or sperm velocity. Previously available studies on human semen quality are, when taken together, suggestive of an effect of EDB on sperm concentration but are inadequate to evaluate potential effects on other semen characteristics. (In our previous longitudinal study of 12 workers with about two months exposure to EDB at levels comparable with those found in the present study ${ }^{20}$ only a statistically significant decrease in sperm velocity and a marginally significant decrease in semen volume were noted when pre- and post-exposure samples were compared. The lack of observed effects on most semen characteristics may be due to an insufficient sample size and the fact that early stages of spermatogenesis would not be observable over the period of study as well as the short duration of exposure. The lack of effect of EDB on sperm velocity in the present study may suggest a transient early effect of EDB which is not observable after long term exposure, when the percentage of motile sperm appears to be significantly reduced but not the velocity of the remaining (motile) sperm.) The effect of EDB on semen quality is also consistent with the observation that certain other alkylating agents, such as some cancer chemotherapy agents, and the structurally similar pesticide dibromochloropropane (DBCP) also affect spermatogenesis (see review by Wyrobek et $^{\mathbf{a}^{36}}{ }^{36}$ ).

The number of subjects studied may limit the ability to detect small changes in certain semen characteristics due to exposure even if such differences are really present. In the case of sperm concentration a sample of 46 exposed and 43 unexposed men was sufficient to have had an $80 \%$ chance of detecting a $32 \%$ or greater decrease in mean sperm concentration in the exposed group compared with the mean of our unexposed group at a two sided alpha level of 0.05 (using a square root transformation of the data). In the case of semen volume our sample size permitted an $80 \%$ chance of detecting a $25 \%$ decrease in mean volume in the exposed group compared with the mean of our unexposed group (using a log transformation of the data); similarly, for sperm velocity, an approximately $10 \%$ decrease in path length or distance velocity could have been detected in exposed workers. Thus smaller true differences between these groups for these semen characteristics could not be determined with confidence in the present study population. In the case of YFF bodies the sample size was sufficient to detect an approximately $26 \%$ difference between the two groups at an alpha level of 0.05 and
$80 \%$ power. It should be noted, however, that consid- $\frac{3}{Q}$ erable variation in these measurements, probably due to the subjective nature of the scoring method, was $\overrightarrow{\vec{F}}$ observed. For 50 subjects for whom replicate slides were read, the absolute difference in percentage of $\frac{}{O}$ YFF bodies between pairs of slides ranged from 0 to $\overline{\bar{\omega}}$. $2.2 \%$ (mean $0.6 \pm 0.46 \%$ ), representing an approxi- $\widehat{\nabla}$ mately $50 \%$ variation on average from the mean of $1 \cdot 2-1 \cdot 3 \%$ in the two groups. In view of these technical difficulties and the fact that considerable controversy $\overrightarrow{0}$ exists as to the meaning of these fluorescent bodies $\overrightarrow{-}$ (AJ Wyrobek, personal communication), the results $\vec{\sigma}$ for this assay should be interpreted with extreme cau-ठ tion.

Possibly the results of the study may be biased if systematic differences exist between the two groups $\vec{i}$ with respect to participants and non-participants- $\omega$ for example, if men with suspected reproductive prob- $\vec{V}$ lems were more likely to participate in the exposedo group than in the unexposed group or vice versa. All $\rightarrow$ currently exposed workers were given individuals explanations of the purpose of the study before the field phase and the participation rate was high with $\vec{\bullet}$ the exception of the sixth plant located during the field study. There were no clear differences between participants and non-participants with respect too demographic characteristics, and reasons given for non-participation were generally unrelated to factors which may potentially affect semen quality. Random $\frac{\alpha}{\mathcal{D}}$ selection of 50 (paid) volunteers from the control population was done to minimise the possibility of $\overrightarrow{\overrightarrow{0}}$ selection bias in this group. Thus we consider it 3 unlikely that selection bias could explain the results of this study.

Several other factors that differed between the exposed and unexposed groups were found to be 3 significantly related to semen quality in this popu-o lation. It is well established that abstinence time. affects both semen volume and concentration ${ }^{37}$ and in this population as well longer abstinence times were associated with an increase in both these param-음 eters. The age of the sample at analysis is also known $>$ to affect strongly sperm viability, motility, and을. velocity ${ }^{38}$; in the present study none of the samples $\tilde{N}$ exceeded two hours from ejaculation to videotaping. (average 40 minutes in each group) and no effect of ${ }_{0}$ sample age was observed, supporting the view that analysis of samples within two hours of collection is satisfactory. Increasing subject's age was, however 0 significantly related to a decrease in semen volume, sperm motility and viability, and the proportion of ? normal sperm but to an increase in sperm concen- 0 tration. The subject's ethnic background also

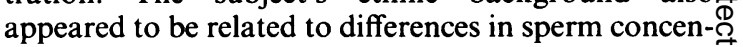
tration, morphology, and morphometry, both if $\underset{\Omega}{\mathbb{D}}$ whites v non-whites or if whites, Filipinos, or othero 
non-whites were considered. No other potentially confounding factors were found to explain a significant amount of variation in semen characteristics with the exception of an apparent association of caffeine consumption with lower sperm concentrations and alcohol use with higher sperm velocity. Whether these are causal or spurious associations remains to be established. No effect of cigarette smoking or marijuana use were observed in this population, although both have been reported to affect semen quality by some authors (see review by Wyrobek $e a^{36}$ ) and both were found to be significantly related to cytogenetic changes in this population. ${ }^{21}$

\section{BIOLOGICAL SIGNIFICANCE OF CHANGES IN}

\section{SEMEN QUALITY}

In the present study eight exposed and three unexposed workers reported in the questionnaire having had problems having children, but in no case was the caused cited as the man's in the eight cases where a doctor was consulted (one case in each group was of unidentified cause). The number of participants was clearly insufficient, however, to evaluate quantitatively fertility or reproductive outcomes in relation to exposure. There are, however, several lines of established evidence that link poor semen quality with impaired fertility, and some evidence to suggest that alterations in semen quality may be associated with adverse reproductive outcomes where conception has been successful. Subfertility has long been associated with low sperm counts, although it is not unusual for pregnancies to occur where the sperm concentration is consistently below 20 million per $\mathrm{ml}^{3940}$ The importance of sperm motility and morphology as well as the number of sperm has been increasingly recognised as indicative of fertility potential in men. ${ }^{4-43}$ Alterations in semen quality have also been linked with adverse reproductive outcomes. For example, several studies have found an association between low sperm concentration and motility or increased abnormal sperm morphology and spontaneous abortions, ${ }^{44-46}$ although a more recent study by Homonnai et al failed to show such as association. ${ }^{47}$ Finally, there is also evidence from animal data, particularly the mouse sperm morphology assay, that there is a high correlation between chemicals with known germ cell mutational activity and their ability to produce morphological changes in the sperm head ${ }^{48}$; this suggests that agents that produce morphological changes in sperm in this species should be regarded as suspect germ cell mutagens in mammals. $^{48}$ Overall, these data support the hypothesis that chemically induced alterations in semen quality increase the risk of impaired fertility and may increase the risk of adverse reproductive outcomes.

\section{Conclusions}

There is a considerable body of research to support the view that impairment of one or more aspect of semen quality is associated with impaired fertility and, less certainly, with adverse reproductive outcomes. Our findings of decreases in sperm count, viability, and motility and increases in certain types of morphological abnormalities among workers with long term exposure to EDB strongly suggest, therefore, an increased risk of reproductive impairment at levels near the NIOSH recommended standard of $45 \mathrm{ppb}$ (as an eight hour TWA) and far below the current OSHA standard of $20 \mathrm{ppm}$.

We are grateful for the help of $\mathrm{R}$ Souza in conducting this study and for the clerical help of B Walpole, C Battaglia, F Guerra, and D Bates. We also thank Drs W Halperin, M Thun, A Wyrobek, R Jeyendran, J Overstreet, and S Samuels for their helpful comments.

Requests for reprints to: Dr S M Shrader, Experimental Toxicology Branch, National Institute for Occupational Safety and Health, 4676 Columbia Parkway, Cincinnati, Ohio 45226, USA.

\section{References}

I National Institute for Occupational Safety and Health. Criteria for a recommended standard. Occupational exposure to ethylene dibromide. Cincinnati: NIOSH, 1977. (NIOSH publ No 77-221.)

2 Environmental Protection Agency. Ethylene dibromide: position document No 4. Washington: EPA Office of Pesticides Programs, 1983.

3 US Department of Labor. Occupational Safety and Health Administration. Notice of proposed rulemaking: occupational exposure to ethylene dibromide. Federal Register 1983; 48:45956-6003.

4 National Institute for Occupational Safety and Health. Testimony on the occupational safety and health administration's proposed rulemaking on occupational exposure to ethylene dibromide. Washington: NIOSH, 1984.

5 National Institute for Occupational Safety and Health. Ethylene dibromide (rev). (Current Intelligence Bulletin No 37.) Cincinnati: NIOSH, 1982. (NIOSH publ No 82-105.)

6 Amir D. The sites of the spermicidal action of ethylene dibromide in bulls. $J$ Reprod Fertil 1973;35:519-25.

7 Amir D. Individual and age differences in the spermicidal effect of ethylene dibromide in bulls. J Reprod Fertil 1975;44:561-5.

8 Amir D, Esnault C, Nicolte JC, Conrot M. DNA and protein changes in the spermatozoa of bulls treated orally with ethylene dibromide. J Reprod Fertil 1977;51:453-6.

9 Amir D, Lavon U. Changes in total nitrogen, lipoproteins and amino acids in epididymal and ejaculated spermatozoa of bulls treated orally with ethylene dibromide. J Reprod Fertil 1976;47:73-6.

10 Amir D, Volcani R. Effects of dietary ethylene dibromide in bull semen. Nature 1965;206:99-100.

11 Eljack AH, Hrudka F. Pattern and dynamics of teratospermia induced in rams in parenteral treatment with ethylene dibromide. J Ultrastruct Res 1979;67:124-34. 
12 Bondi A, Alumot E. Effect of EDB fumigated feed on animals. (Final technical report PL-480.) Washington: US Department of Agriculture, 1966.

13 Edwards K, Jackson H, Jones AR. Studies with alkylating esters II. A chemical interpretation through metabolic studies of the antifertility effects of ethylene dimethanesulphonate and ethylene dibromide. Biochem Pharmacol 1970;19:1783-9.

14 Short R, Winston J, Hong C, Minor J, Lee C, Seifter J. Effects of ethylene dibromide on reproduction in male and female rats. Toxicol Appl Pharmacol 1979;49:97-105.

15 Wong O, Utidjian MD, Korten VS. Retrospective evaluation of reproductive performance of workers exposed to ethylene dibromide. J Occup Med 1980;21:98-102.

16 White GL, Lybarger J. Health hazard evaluation. Cincinnati: Houston Chemical Co, 1978. (NIOSH HETA 77-119-481.)

17 Griffiths J, Heath R, Davido R. Spermatogenesis in agricultural workers potentially exposed to ethylene dibromide. Washington: Environmental Protection Agency, 1978. (Interim report.)

$18 \mathrm{Ter}$ Haar G. An investigation of possible sterility and health effects from exposure to ethylene dibromide. (Banbury report No 5.) New York: Cold Spring Harbor Laboratory, 1980.

19 Rogers BJ, Fujita JS, Najita L, Hale RW. Reduction of sperm concentration in a population exposed to ethylene dibromide. Proceedings of the 6th annual meeting of the Andrology Society. J Androl 1981;2:35-6.

20 Ratcliffe JM, Schrader SM, Meinhardt T, et al. Semen quality in timber fumigators exposed to ethylene dibromide. Cincinnati National Institute for Occupational Safety and Health, 1984. (Report No TA-83-244.)

21 Steenland K, Carrano A, Ratcliffe JM, Clapp DE. Ashworth L, Meinhardt TM. Cytogenetic changes in papaya workers exposed to ethylene dibromide. Mutat Res 1986;170:151-60.

22 Clapp DE. Industrial hygiene survey of papaya fumigation facilities in Hawaii. Cincinnati: National Institute for Occupational Safety and Health, 1984.

23 National Institute for Occupational Safety and Health. Method 1008: 1,2 dibromoethane. NIOSH manual of analytical methods. 3rd ed. Cincinnati: NIOSH, 1984. (NIOSH publ No 84-100.)

24 Albertson P, Chang TSK, Vindivich D. Optimal parameters for the quantitative assessment of sperm motility. $J$ Androl 1984;5:22.

25 Overstreet JW, Katz DF, Hanson FW, Fonseca JR. A simple inexpensive method for objective assessment of human sperm movement characteristics. Fertil Steril 1979;31:162-72.

26 Jenks JP, Consentino MJ, Cockett ATK. Evaluating sperm motility: a comparison of the Rochester motility scoring system versus videomicrography. Fertil Steril 1982;38:756-9.

27 Belsey MA, Moghissi KS, Eliasson A, Paulsen CA, Gallegos AJ, Prasal MRN. Laboratory manual for the examination of human semen and semen cervical mucus interaction. Press Concern, Singapore, 1980.

28 Zaneveld LD, Polakoski KL. Collection and physical exam-
Ratcliffe, Schrader, Steenland, Clapp, Turner, Hornung ination of the ejaculate. In: Hafez ESE, ed. Techniques human andrology. Amsterdam: Elsevier, 1977:146-72.

29 Eliasson R, Treichl L. Supravital staining of human spermatozo Fertil Steril 1971;22:134-7.

30 Jeyendran RS, Van de Ven HH, Perez-Pelaez M, Crabo BG, Zan eveld LJD. Development of an assay to assess the functionat integrity of the human sperm membrane and its relationship to. other semen characteristics. J Reprod Fertil 1984;70:219-28. S

31 Kapp RW, Jacobsen CB. Analysis of human spermatozoa for $\vec{D}$ chromosomal nondisjunction. Teratogenesis Carcino Mutagen 1980;1:193-211.

32 Statistical Analysis Systems, Inc. User's guide. North Carolina:SAS, 1982.

33 Statistical Analysis Systems, Inc. User's guide. North Carolina SAS, 1979.

34 Kleinbaum DG, Kupper LL. Applied regression analysis. Masรึ Duxbury Press, 1978.

35 Neter J, Wasserman W. Applied linear statistical models. Home wood, II: Irwin, Inc, 1974.

36 Wyrobek AJ, Gordon LA, Burkhart JG, et al. An evaluation of human sperm as indicators of chemically induced alterations of spermatogenesis in man. Mutat Res 1983;115:73-148.

37 Schwartz D, Laplanche A, Jouannet P, David P. Within-subject variability of human semen in regard to sperm count, volume? total number of spermatozoa and length of abstinence. $L$ Reprod Fertil 1979;57:391-5.

38 Makler A, Zaidise I, Paldi E, Brandes JM. Factors affecting sperm motility. I. In vitro change in motility with time after ejaculation. Fertil Steril 1979;31:147-54.

39 Smith KD, Steinberger E. What is oligospermia? In: Troen poo Nankin HR, eds. The testis in normal and infertile men. New York: Raven Press, 1977:489-503.

40 Overstreet JW. Semen analysis. Infertility in the male. Ann Inter Med 1985;103:906-19.

41 Bartak V. Sperm velocity and morphology in 1727 ejaculates wit normal sperm counts. Int J Fertil 1973;18:116-8.

42 Eliasson R. Semen analysis. Environ Health Perspeç 1978;24:81-5.

43 Steinberger E, Rodriguez-Rigau LJ. The infertile couple. $J$ Andr $\overrightarrow{\vec{\Phi}}$ 1983;4:111-8.

44 Furuhjelm M, Jonson B, Lagergren C-G. The quality of huma $\bar{\Phi}$ semen in spontaneous abortion. Int J Fertil 1962;7:17-21.

45 Joel CA. New etiologic aspects of habitual abortion and fertility with special reference to the male factor. Fertil Ster 1966;17:374-80.

46 Czeizel C, Hancsok M, Viczian M. Examination of the semen of habitually aborting women. Orv Hetil 1967;108:1591-5.

47 Homonnai ZT, Pax GF, Wiess JN, David MP. Relation between semen quality and fate of pregnancy: retrospective study oळ 534 pregnancies. Int J Androl 1980;3:547-84.

48 Wyrobek AJ, Gordon LA, Burkhart JG, et al. An evaluation of the mouse sperm morphology test and other sperm tests in nonhuman animals. Mutat Res 1983;115:1-72. 